\title{
Reseña
}

\section{De tiempos y creencias}

\author{
Hay tantas fes | Lapso \#5 MaTPsiL | 2020 \\ María Eugenia Castro
}

Universidad Nacional de Córdoba, Argentina

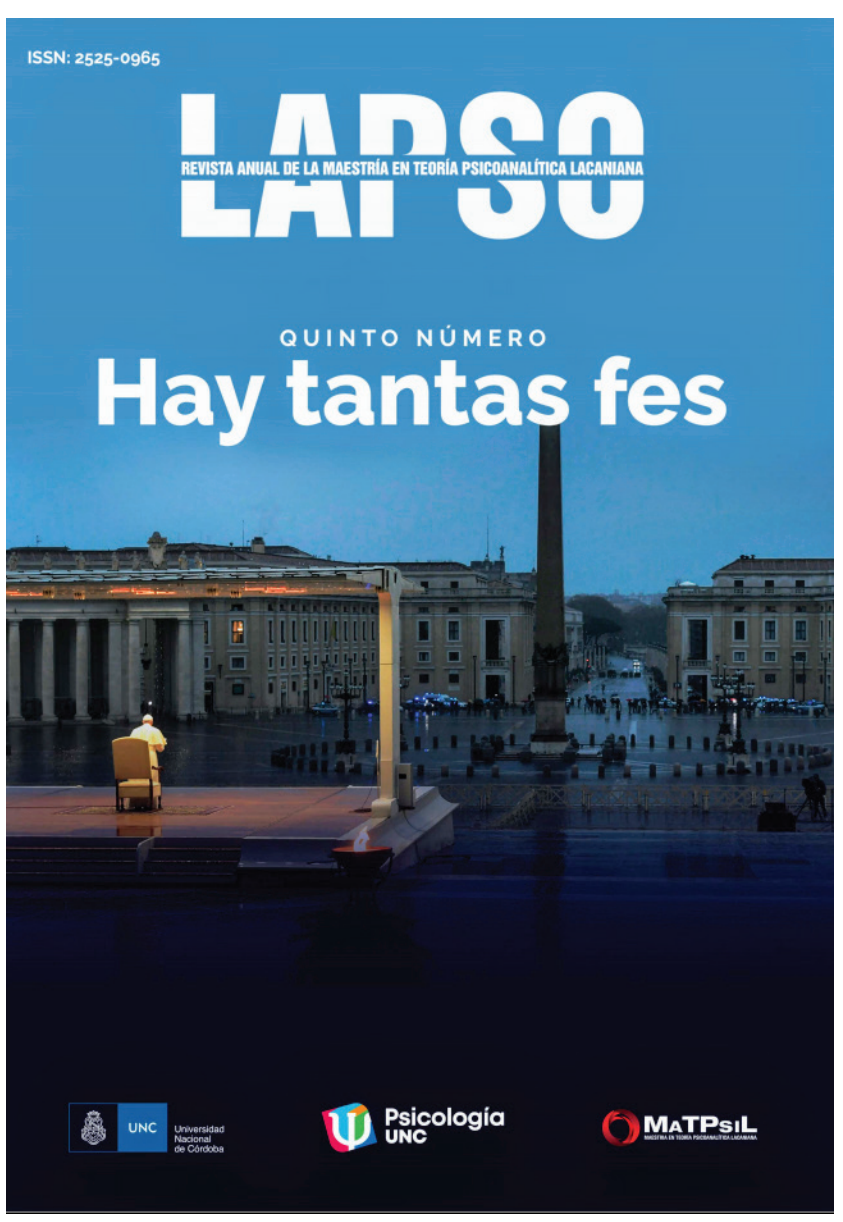

Editorial - El ocaso de lo social, la fe en la palabra. Marco Rubén Alfieri

TEORÍA Y CONCEPTOS:

Religión-Prescindir para servirse de... Freud, un científico. Sarab Abitbol

Una civilización sin Dios. Emilio Vaschetto y Jorge Faraoni

La creencia en el parletre político: les trumains. Hernan Brizio

El éxito de lo religioso. Gerardo Battista

Apostar a creer allí, en el síntoma. Ivanna Ramé

$¿$ ¿Un robot que sea sujeto?. Ivana Nabir Fuentes

ENTREVISTA LAPSO:

Eric Laurent. Videoentrevista

INTERVENCIÓN ESPECIAL:

¿Hay psicoanálisis? Implantación de un deseo/trasmisión de una Praxis. Baby Novotny

INTERSECCIONES:

Tres relatos de fe y algunas preguntas. Paula Hunziker

El poder creador de las metáforas. Entrevista a Elsi San Martin

Ante el desamparo, comprás amparo. Entrevista a Alejandro Seselovsky

Sería ingenuo tener fe ciega en el mercado. Entrevista a Haroldo Montagu

Hacer ferias, es solo cuestión de fe. Diana Paulozky

PUBLICACIONES:

Creencias. María José Ghione

Desarraigados, una reseña. Diego Gareca Figueroa

Apostillas del TyA Córdoba: "Paradojas de la prevención".

Gonzalo Guzmán

EVENTOS Y PRODUCCIONES:

El acontecimiento Laurent o la vitalidad de un desir. Guido Coll

Videoconferencia de Fabián Fajnrwaks en la Facultad de Psicología de la UNC: “¿Hay un feminismo lacaniano?”. Luciana Szrank

La ciudad de tus desechos. Suquía Urbano/Taller Mediterráneo. Marcelo Fiorito

“Hay tantas fes” es la quinta edición de la Revista Lapso de la Maestría en Teoría Psicoanalítica Lacaniana. ¿Qué es la fe? ¿Cuáles son las respuestas que se presentan en los sujetos de hoy, tras la caída de las tradicionales referencias simbólicas? Son algunos de los interrogantes de este número en el que se podrán encontrar interesan- tes reflexiones y desarrollos acerca del discurso capitalista, la religión, el mercado y la ciencia.

Se destaca en este número, un esfuerzo de escritura desde los aportes de Éric Laurent, referencia ineludible de la teoría psicoanalítica lacaniana contemporánea cuya llegada a la capital de nuestra ciudad tomó valor

eugecoco87@gmail.com 
de acontecimiento tras recibir el Doctor Honoris Causa, en la Universidad Nacional de Córdoba. Una interesante conversación con él, en Entrevista Lapso, nos dará la oportunidad de conocer su lectura actual de aportes de Jacques Lacan en torno a la política, la fe, el discurso capitalista y los foros en los que se despliegan los debates contemporáneos. Abordará en esta conversación, la relación de la fe con el final de un análisis, permitiéndonos ubicar su lugar en el sujeto.

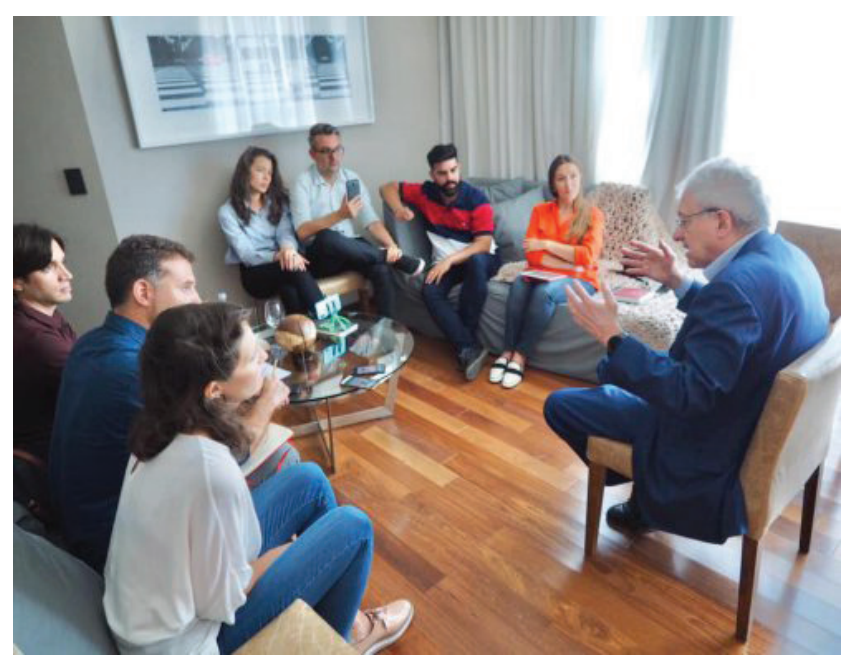

En la sección Intervención Especial, María E. (Baby) Novotny, traza un recorrido acerca del desarrollo y establecimiento del psicoanálisis en Córdoba, reconociendo la oportunidad que la Escuela de la Orientación Lacaniana (EOL) posibilita al hacer existir al psicoanalista, alojándolo y contando como Otro en el cual resulta posible creer.

Podremos reconocer también en Intersecciones, valiosos entrecruces del psicoanálisis con otros discursos contemporáneos que proponen una lectura de diferentes problemáticas presentes en la actualidad. ¿En qué creen los sujetos hoy?

Desde aportes de la filosofía, Paula Hunziker, nos invitará a conocer tres escenas y relatos de fe a partir de la película $E l$ sacrificio de Tarkovsi para pensar el sentido o el sinsentido de la fe religiosa en el mundo moderno. Una conversación con la Licenciada en Teología Elsi San Martín advierte el valor y compromiso de las acciones políticas y creencias como activista social feminista, considerando lineamientos políticos y el boom de movimientos de esta época. Estos aportes conversan también con los desarrollos de Fabián Fajnwaks en su conferencia ¿Hay un feminismo lacaniano?, recuperados por Luciana Szrank en la sección Eventos y Producciones.
A través del psicoanálisis, Diana Paulozky permitirá visibilizar el valor del deseo como verdadero acto de fe y ubicará en los fundamentos de la praxis psicoanalítica su relación con el arte y la creencia en lo real. Por último, Haroldo Montau, desde una articulación precisa que parte del campo de la Economía, reflexiona acerca de la angustia en los sujetos de hoy.

Algunas articulaciones conceptuales de la episteme lacaniana que bordean el eje temático de la presente publicación se encuentran en la sección Teoría y Conceptos. Luego de distinguir junto a Sarah Abithol la fe en los significantes de la fe religiosa y su recorrido por el paso de Freud en el judaísmo y su afinidad con la ciencia, Emilio Vaschetto y Jorge Faraon, advierten en su artículo la importancia del cuerpo y la creencia del sujeto de hoy, trasmitiendo su importancia para responder a lo imposible de soportar de su humanidad. Reflexionará también sobre algunas características de la sociedad actual, Gerardo Battista, quien observa un triunfo de lo religioso como uno de los devenires en la época de la caída del Nombre del Padre, y considera cómo la creencia opera en sí misma como terapia.

Pero además, se presentan importantes aportes teóricos vinculados a la creencia en un diálogo con la práctica clínica. Publicaciones, nos acerca interesantes libros y trabajos que pueden colaborar a una lectura de los sujetos en la actualidad. Maria José Ghione, nos presentará Creencias (2019), una nueva compilación de trabajos de la Colección de la Orientación Lacaniana en el que se puede reconocer a éstas como un arreglo con lo real. Diego Gareca Figueroa nos aproxima al libro Desarraigados (2016) y su riqueza para establecer casos clínicos atravesados por el desarraigo que implica la extracción de la tierra fértil del lenguaje y del registro simbólico. Por su parte, Gonzalo Guzmán nos invitará a reconocer algunas líneas de trabajo del departamento del TyA, en Paradojas de la prevención (2020), en la cuarta edición de la colección Apostillas.

A través de los mencionados escritos, este número nos invita a conocer perspectivas diversas y precisas sobre algunos de los avatares que transitan los sujetos de hoy. Nos encuentra así, con una valiosa oportunidad para reconocer cómo los síntomas y devenires que emergen en las contingencias actuales adquieren un carácter propio. Un rasgo de nuestro tiempo que advierte la dimensión de un arreglo con el que los sujetos se encontraron en distintas épocas: las creencias. 